\title{
INTERACTIVE INTERNET-BASED DISASTER RISK INFORMATION SYSTEM FOR TSUNAMI-HIT ACEH PROVINCE OF INDONESIA
}

\author{
Nasaruddin, Ardiansyah \& Khairul Munadi \\ Syiah Kuala University, Indonesia \\ nasaruddin@unsyiah.ac.id; ardiansyah@unsyiah.ac.id; \\ khairul.munadi@unsyiah.ac.id
}

\begin{abstract}
Aceh is facing not only tsunami threats, such as the 2004 Indian Ocean Tsunami that caused massive devastation to the region, but also other natural disasters, such as earthquakes, landslides and volcanic eruptions. One of the factors that can contribute to reducing disaster is the availability and accessibility of risk knowledge. This knowledge is essential to keep people aware and well prepared to face impending disasters. This study proposes an interactive internet-based disaster risk management information system (DRMIS) for the Aceh province. The DRMIS serves as an online disaster risk map as well as a tool for communicating risk knowledge. An iterative approach to designing, developing and implementing the system is introduced. The DRMIS, which is currently accessible online, and its features, are described. The proposed system offers interactive display of four thematic maps, covering hazards, vulnerability, capacity and disaster risk of the most common natural hazards in Aceh.
\end{abstract}

Keywords: Interactive maps, disaster information, DRMIS; internet-based service, disaster risk maps.

\section{INTRODUCTION}

The huge earthquake and tsunami that occurred on December 26, 2004 should be considered as a valuable lesson for Indonesia, in general, and Aceh, in particular, specifically in terms of preparedness and disaster risk reduction (DRR) efforts. Significant focus should be placed on this issue as earthquakes still frequently occur in the region. Furthermore, Aceh is very prone to various other natural hazards, including volcanic eruptions, floods, landslides and 
strong wind (Nasaruddin et al., 2011). One of the factors and a countermeasure for DRR is the availability of an adequate information system on the disaster risks, as this information can play an important role in three stages: prior to, during and after a disaster occurs (Wategama, 2007; UN-APCICT). People who live in disaster-prone areas will be directly affected. They need adequate information about hazards and the risks that they are facing. Quick and precise information can make them more alert and better prepared to take mitigation activities and emergency action after the disaster. Furthermore, an information system is considered important in developing, implementing, evaluating and recording plans and programs to address current and future risks (UN-APCICT; Yanhua et al., 2009). It can support effective decisionmaking processes in disaster risk management which requires information on hazards, vulnerability and the risk conditions of a specific area.

The effectiveness of disaster risk management greatly depends on the efficiency in managing the relevant information (Siekierska \& Williams, 2005; Cheng et al., 2010; Zemp, 2011). In disaster situations, society and disaster mitigation agencies require current information, which is usually associated with geospatial information for making quick decisions and taking correct and measurable actions (Luiz et al., 2012; Cozannet et al., 2014). Information exchange between the disaster mitigation agencies and the community will be effective if the mechanisms and tools are available (Sutanta et al., 2010). An appropriate mechanism is very important to integrate data and workflow management between disaster risk management authorities and stakeholders. Furthermore, it will be very useful if a supporting tool that enables wider access to the system is available, such as an internet-based information system for various types of geodata of disasters and for other purposes, such as agricultural insurance (Najafabadi et al., 2012), that can be accessed online, at any time and from anywhere. Moreover, current development of spatial databases technology, geographical information systems (GIS), internet and wireless mobile network can further enhance the effectiveness of disaster management (Tahir, 2007; Jeberson \& Sasipraba, 2010; Cozannet et al., 2014; Abdurrahman, 2014).

Several agencies have developed web-based disaster risk information systems for their own purposes in their countries. For example, a geoportal of natural hazards and risks has been implemented in Georgia (CENN, 2012), in which the hazards and risk maps are generated using Google facilities. Another example, a web-based disaster risk explorer, has been proposed by the CEDIM project "Riskmap Germany" (Muller et al., 2006; Kohler et al., 2006). It visualizes hazards, vulnerabilities, and risks of various natural and man-made disasters that occur in Germany. However, the Aceh province of Indonesia has no such mechanism or tool that can be used for managing the disaster risks 
and hazards, irrespective of the fact that the province is known as one of the most disaster prone regions (Nasaruddin et al., 2011; Nasaruddin, 2011). The early stage of disaster management in Aceh requires various information at district and provincial levels that should be collected, mapped and uploaded through a system. Therefore, an interactive internet-based information system is crucial for enhancing DRR iniatives in Aceh.

Previous studies (CENN, 2012; Muller et al., 2006; Kohler et al., 2006) have not clearly described their methods and approaches to develop webbased disaster risk information systems. Authors have merely described their approaches at the macro-level, rather than providing practical and easy to replicate solutions. Thus, a more clear and descriptive method is necessary for future reference.

This study discusses the development and implementation of an internetbased disaster risk management information system (DRMIS) in Aceh. The main objective of this study is to provide online resources of DRMIS that are accessible to Aceh government officials, researchers and the community. Besides, a more descriptive approach to developing a web-based disaster risk information system is also presented. This research is an extension of the work of Nasaruddin (2011); and Nasaruddin et al. (2010), which was supported by the Aceh government through a DRR project for Aceh (DRR-A). In Nasaruddin et al. (2011), the natural hazard information system was introduced and the preliminary prototype of DRMIS was developed (Nasaruddin et al., 2010).

The proposed DRMIS is implemented on an internet-based GIS platform that provides the disaster risk information at the Aceh regional level because this level is the first to assume the responsibilities to manage such information. It can be used as a disaster risk information platform for integrating all relevant data, knowledge and decision support tools. Furthermore, this study discusses the conceptual model of the interactive information systems, network topology and prototyping for the DRMIS. The DRMIS is designed on the basis of an iterative design method, in which each step in the iterative process can be revisited until the best performance is obtained. The proposed DRMIS mainly focuses on the Aceh region because the disaster data currently available encompass only 10 types of disasters in Aceh. However, the system can be extended to a wider area, such as the national level, as long as the required data are available.

The DRMIS hosts various interactive and thematic maps of risk components, including hazard, vulnerability, capacity and risks of natural hazards in Aceh. We note that hazard, vulnerability, and risk identification are the starting point for any DRR process and activity (Lim \& Chang, 2012). Moreover, risk 
identification is a fundamental step for obtaining a risk map. The risk map should be the first resource for any disaster risk decision, where the entire process of risk assessment can be beneficial for the representation of GIS (Kraak, 2004). The thematic maps are also useful for monitoring and forecasting the area of a disaster. The maps play an important role in GIS for spatial analysis and the geospatial data handling process (Chang \& Park, 2004). Furthermore, DRMIS is motivated by the advantages of web GIS that can support multiusers and be accessible from anywhere and any place and at any time through the web. Thus, disaster management agencies will have sufficient reference data and information toward effective disaster preparedness, response and recovery. Furthermore, it can be effective in notifying the risks involved to the disaster mitigation agencies so that they will be able to understand such risks and take action accordingly.

The proposed DRMIS can be seen as a visual risk communication tool for reducing various disaster risks in Aceh. The risk communication tool is intended to produce an appropriate disaster response and mitigation (Lindell et al., 2007). Hence, the people will be aware about the risk and will be motivated to take preventive actions as well as be prepared for an emergency response. Accordingly, the research contributions of this study can be summarized as follows: (i) a comprehensive method of developing DRMIS that comprises detailed risk mapping components and efficient web-based data visualization of hazards, vulnerability, capacity and risk maps of 10 types of disasters in the Aceh region; and (ii) the implementation of DRMIS for online access via the internet that can be used for effective disaster management by the government of Aceh and disaster mitigation agencies.

\section{METHODOLOGY}

The development method in this study is an iterative design method (Niv et al., 2002); or waterfall model based on service-oriented architecture (SOA) concept (Lim \& Chang, 2012) for DRMIS, in which people without spatial data and knowledge of map design can utilize spatial information available through an automated service. The SOA has the ability to obtain the dynamic, distributed, reconfigurable and flexible service system via the Internet so that requirements from many different users can be fulfilled. The concept of SOA is applied to internet-based GIS applications, such as DRMIS, by publishing maps or other geospatial data as a web service that can be consumed by other machines. A web server hosting an internet-based GIS application retrieves the web service and displays it as an interactive map. In the SOA concept, the geospatial data do not have to be in the same machine or network; it can be 
anywhere. Thus, although the DRMIS is developed with Aceh data, in reality, it can be extended to other areas as long as the map's data are accessible via web service and their contents are similar to existing disaster map layers in the system.

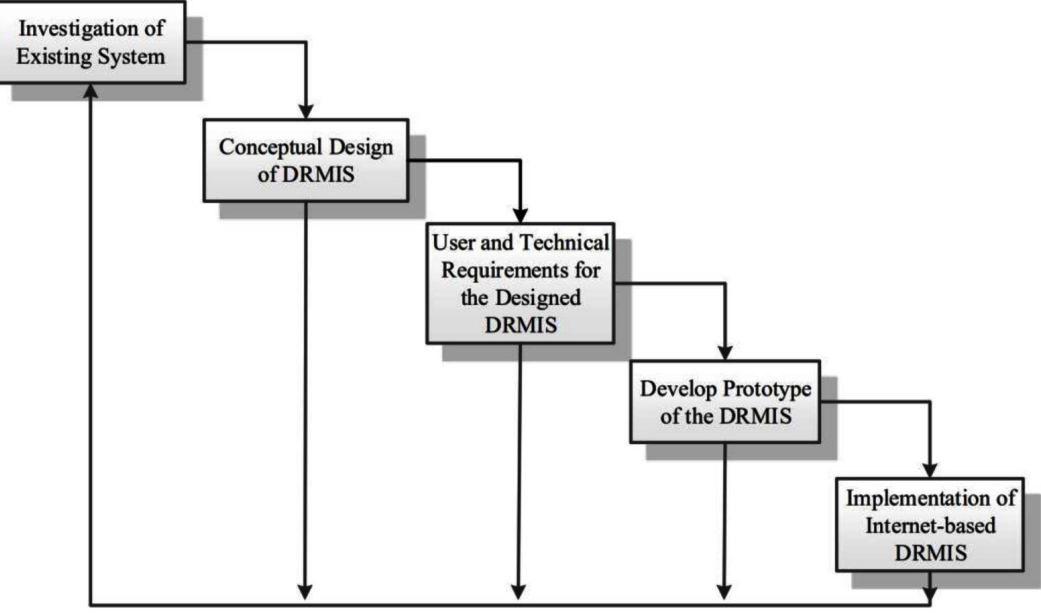

Figure 1. Waterfall method for implementing DRMIS.

Designing, developing and evaluating the interactive internet-based DRMIS involve several steps as shown in Figure 1. The steps in Figure 1 are described as follows:

The first step is preliminary assessment, which is conducted to identify the existing system that is similar to the proposed DRMIS. It provides the opportunity to continue some studies with national institutions that have responsibility for disaster information management. The information gathered during this assessment provides a useful snapshot for the development of DRMIS activities.

The conceptual design is a very important step to study in detail how the system will be constructed to perform necessary tasks. It is focused on the information requirements that will be processed in DRMIS, software and hardware requirements and the interface design.

User and technical requirements are the main parts for developing the system. The development of the DRMIS takes into consideration the user requirements, such as local governments, academia and research institutions 
and public engaged in disaster risk reduction activities. This ensures that the target system truly meets the requirements of its users. The user requirements are obtained by direct and indirect communications with users' participation. From the users' information, technical requirements can be obtained, including system architecture, network topology, user interface design and publishing the service.

At this stage, the prototype is developed on the basis of the SOA concept in which the platform is implemented in a four-layer architecture. The four-layer architecture is data layer, thematic layer, service layer and application layer. Each layer has different functions and provides interface to the other layer. This will make the system compatible with a wide range of functions and extendable to implement new ones. The SOA concept allows the remote user to access the system, exploit data and retrieve the required information. The prototype should be capable of easy dissemination and visualization, flexible retrieval and appropriate analysis of the data. The developed prototype is tested and evaluated to ensure that all the user and technical requirements have been fulfilled. If the prototype has not satisfied all the requirements appropriately, the development steps will be repeated and new prototype will be constructed. This iterative process will continue until the optimal prototype is produced.

The final step of this research is the implementation of DRMIS in the real system. The implementation stage will use the prototype, which gives the best performance and deploys it as a real system that can be accessed by the public via the Internet. Thus, the last version of DRMIS prototype becomes the implemented Internet-based DRMIS.

\section{THE DEVELOPMENT OF DRMIS}

In this section, the development phases of DRMIS are described, including risk mapping concept, the conceptual model, system configuration and network topology and the DRMIS prototype.

\section{Risk Mapping Concept}

Disaster risk can be defined as a potential loss caused by a disaster in an area during a certain period of time and it may come in the form of death, injury, illness, mental threatened, loss of sense of security, displacement, damage or loss of property and disruption of community activities (BNPB, 2012). Mapping of disaster risk is an important basis for a comprehensive disaster mitigation-based planning. The purpose of a risk map is to clearly identify 
the risks, their distribution and causes in relation to hazards, vulnerability and capacity of a community at risk in the region. The level of disaster risk is attributed to those three components because the disaster occurrance is also influenced by social factors. A risk is becomes a disaster when the capacity of a community to survive a hazard is at a level lower than that of the hazard striking the community (KLH, 2007). The relationship between the disaster risk and its related aspects can be best described by the following equation.

$$
R=\frac{H \times V}{C}
$$

where,

$R$ is disaster risk.

$H \quad$ is hazard or frequency (probability) of certain disaster to occur with particular intensity at a specific location.

$V \quad$ is vulnerability, the expected losses (impact) of a disaster that occur with certain intensity at a specific location. This variable is calculated as exposure (population, assets, etc.) multiplied by the sensitivity for specific disaster intensity.

$C$ is adaptive capacity, the available capacity of a specific location to recover from the disaster.

From Equation (1), we can deduce that if hazard and vulnerability are increased, then the risk will be increased. However, if capacity is increased, the risk will be reduced. The equation also shows that the risk of an area can be derived from hazard, vulnerability and capacity of that area. The contributing elements to each component of hazard, vulnerability and capacity are illustrated in Figure 2 (TDMRC, 2010), which can be grouped into four profiles, i.e., spatial profile, sosio-economics profile, infrastructure profile and institution profile. All elements in each profile can be mapped, and using the GIS technique, the individual maps can be combined to generate hazard, vulnerability and capacity maps, accordingly. Furthermore, the disaster risk map is eventually derived by combining those three maps, according to Equation (1).

The disaster risk intensity is represented by an index value, which is obtained by combining grid index of hazard, vulnerability and capacity maps based on Equation (1). Then, the resulting index is converted to a range from 0 to 1 , where 0 is the minimum value and 1 is the maximum value of risk intensity. Moreover, scoring each element is obtained by utilizing analytical hierarchy process (AHP) approach. It is derived by using eigenvector of hazard, vulnerability, capacity and risk matrices; then the result is normalized 
to the total of 1 . Using the indicator that refers to the national and international documents and also the scoring factor, hazard, vulnerability, capacity and risk indices are classified into five levels as shown in Table 1. These classifications are used at the user interface of DRMIS as in the legend of the maps in the section on result and discussions.
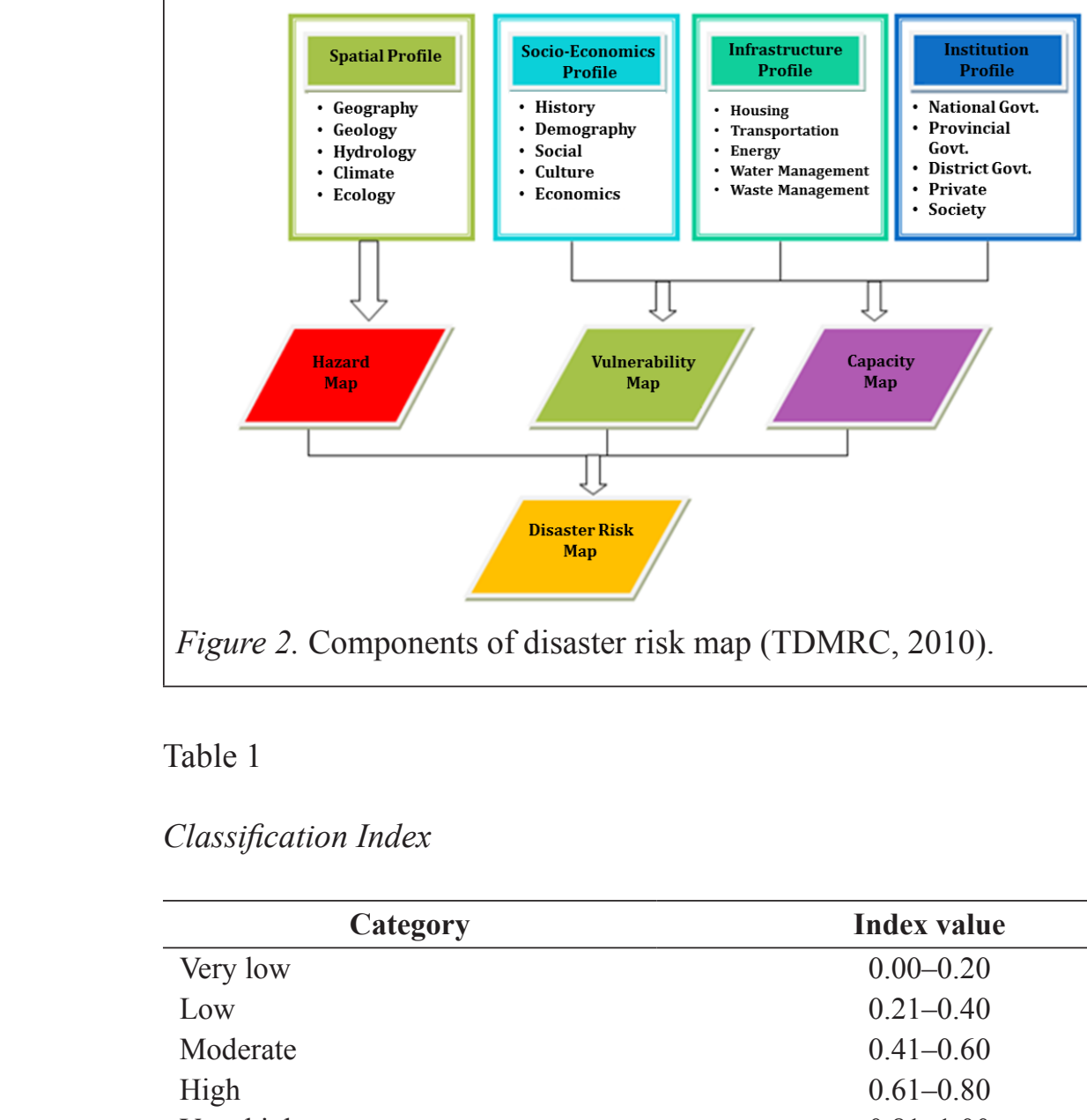

Figure 2. Components of disaster risk map (TDMRC, 2010).

Table 1

Classification Index

\begin{tabular}{lcc}
\hline & Category & Index value \\
\hline Very low & $0.00-0.20$ \\
Low & $0.21-0.40$ \\
Moderate & $0.41-0.60$ \\
High & $0.61-0.80$ \\
Very high & $0.81-1.00$ \\
\hline
\end{tabular}

\section{Conceptual Model}

For the purpose of effective systems implementation, a conceptual model that shows the structure of required data, its relationship and related ouput, is required. In general, the concept of DRMIS is similar to that of the CEDIM risk explorer (Muller et al., 2006). However, DRMIS includes capacity as an 
additional aspect in generating the risk map. The proposed DRMIS conceptual model is illustrated in Figure 3, in which each element has its own activities and processes.

The hazard layer in DRMIS contains source of risks or hazards and their occuring probability, including earthquakes, tsunami and flooding; while the vulnerability layer contains the data related to elements at risk, such as households, schools and bridges. The overlay of hazards and elements at risk indicate the level of disaster risks. Thus, a risk map is a localization map that identifies the possibly affected locations in the event of natural disaster. The goal of the map is to estimate the occurrence probability of a specific hazard, including its intensity and affected area, within a certain period of time.

The advantage of this model is that it can provide necessary information for several phases in the disaster cycle. For example, information on hazards for preparedness can be obtained from the individual hazard map and the vulnerable region can be displayed on the vulnerability map. Besides the thematic maps, DRMIS can be designed to facilitate post-disaster damage and loss assessment, disaster early warning and forecasting. However, our current interest is mainly focused on visualization of hazard, vulnerability and risk maps.

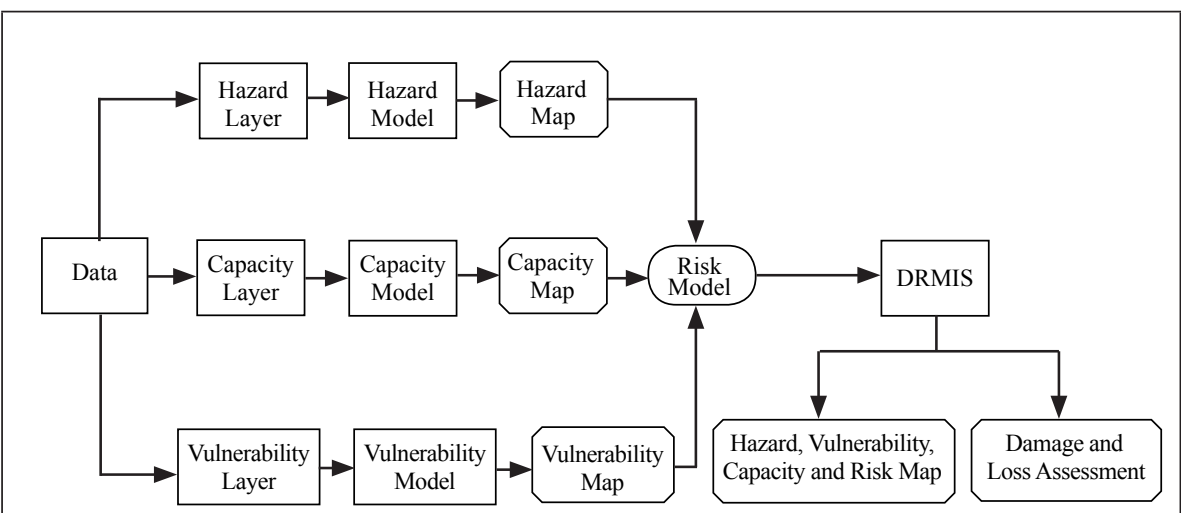

Figure 3. Conceptual model of DRMIS.

In terms of the content, DRMIS can also be seen as an internet-based mapping application that publicly presents the results of risk assessment in Aceh; therefore, it enables people to interactively access the related disaster risk information. It enables users to view and retrieve various maps that visualize different types of hazards and their characteristics, covering hazard maps, 
vulnerability maps, capacity maps and disaster risk maps. It is also developed to function as a portal that provides interactive maps visualization and geodata management. The target users are those who are familiar with the Internet without the need to have technical knowledge in GIS.

To ensure its usefulness to the Aceh context and to sustain its future development, the DRMIS is developed on the basis of the following principles:

- Data and information are collected from related stakeholders, such as local governments, national/international NGOs, spatial data centers and research publications. Those who are in charge of managing the relevant data and information in each institution are invited to be part of the project.

- The chosen technology is reasonably priced, considering the financial situation. Furthermore, the technical solution is sufficiently flexible to accept changes in the future to allow the inclusion of new components.

- The system allows simultaneous access from many concurrent users, such that users from different sectors, including those from related agencies and common users, can access the system at any time and from any place.

\section{Systems Configuration and Network Topology}

In developing an interactive DRMIS, the spatial and temporal data are required to generate the thematic maps, i.e., hazard, vulnerability and risk maps. The spatial data are usually stored as georeferenced shapefiles and sets of shapes, such as points, lines, polylines and polygons, with associated database files. To identify the software requirements for the system, the primary functions must be considered internal to the GIS software tools, that include features as follows:

- Generate hazard, vulnerability, capacity and risk maps for the World Wide Web.

- Pan, zoom, refresh and map manipulation.

- Display features based on the scale.

- Point and click functionality on the map.

- Query functionality.

- Textual content.

To implement the system in the real environment, a configuration system of DRMIS is required. A suitable configuration for DRMIS will provide good reliability and efficiency during the process of data input into the database. The 
configuration system refers to the hardware and software requirements and network topology. The software and hardware requirements for implementing interactive information system of DRMIS are listed as in Table 2; while the required hardware is derived by considering the proposed network topology in Figure 4.

Table 2

Hardware and Software Configuration System

\begin{tabular}{ll}
\hline \multicolumn{1}{c}{ Hardware } & \multicolumn{1}{c}{ Software } \\
\hline Server Computer & ArcGIS Server \\
Desktop Computer & ArcGIS Desktop \\
Hub/switch & Windows Server \\
Router & Database Server \\
Firewall & Web Server \\
\hline
\end{tabular}

The SOA is a web-based service that can be implemented at many different network environments. Therefore, the proposed network topology is based on a three-tier server/client architecture as shown in Figure 4. The network topology refers to the arrangement of server side hardware, cable, client side hardware and other peripherals on the network. It is supported by several required software at server and client sides that is similar to the concept in Zamli et al. (2002). For their communication, server and client realize spatial data transmission from the server to the client. At the client side, it visualizes the spatial data from database service.

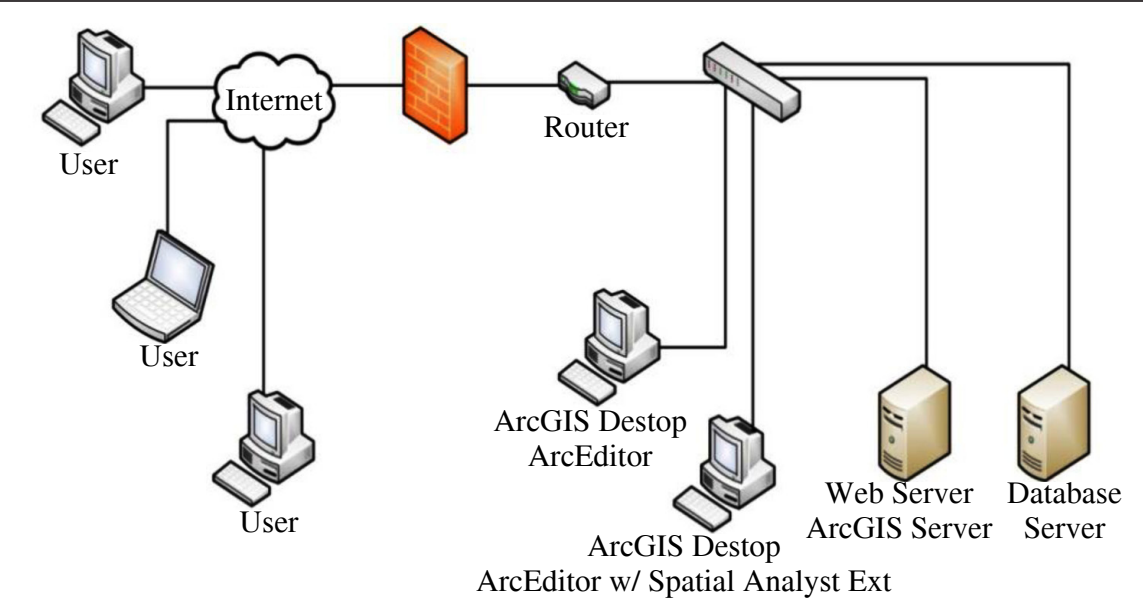

Figure 4. DRMIS configuration and topology. 
This network topology is specifically designed for DRMIS implementation. The topology accommodates the requirements for a distributed information systems network. It is conceived as a component of thematic spatial data infrastructure (SDI), following the standards for Web-GIS services. It enables different users to easily access the information as well as presents the information in a more useful manner for decision-makers.

\section{Prototype}

Several prototypes of DRMIS were built during the systems development. One of the working prototypes that followed the SOA concept and the conceptual model was implemented for a limited usage. It was designed as an interactive web-based application, enabling users to access it using the Internet. The system was developed using the open source software, namely GeoServer as the spatial server, PostgreSQL/PostGIS as the spatial database and GeoExt Web Client library to present GIS information on the Internet. The geoserver, database server and the other software applications were installed in onecomputer configuration as the hardware used in the prototype. The main page of this prototype is shown in Figure 5.

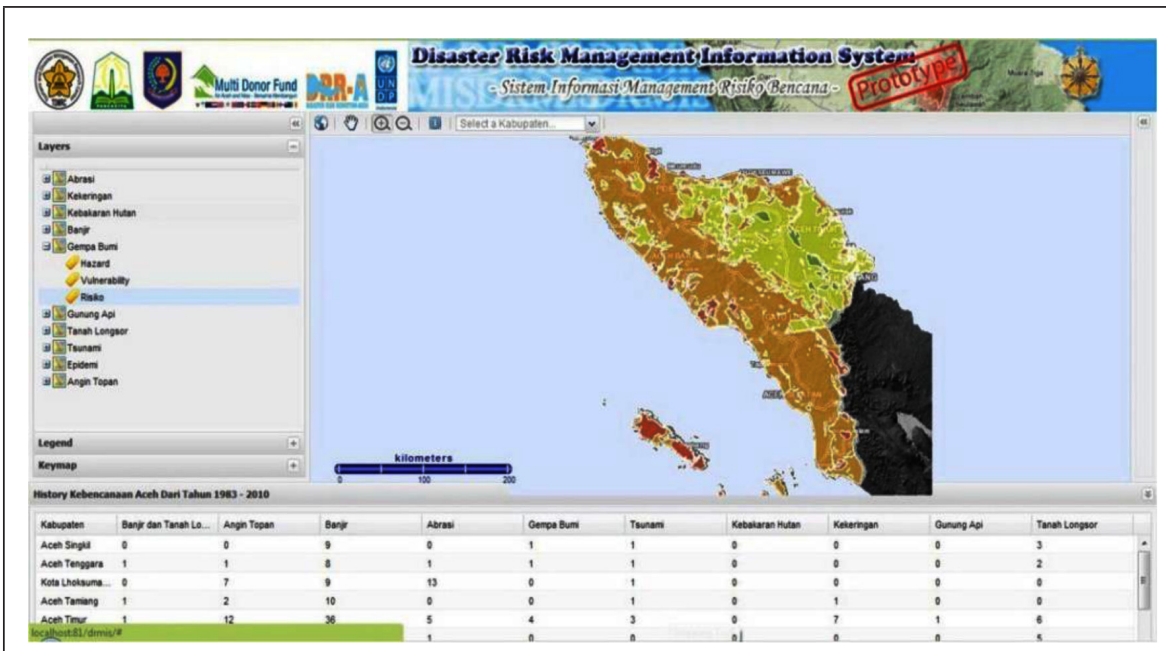

Figure 5. Prototype of DRMIS.

This prototype was intended merely as a model to enable functionality and visibility test of DRMIS. The DRMIS prototype provides the user with a tangible means of comprehending and evaluating the proposed system. Moreover, this prototype was used to elicit feedback from potential users regarding their needs. It is also a practical way for cultivating and building 
user participation and commitment to the implementation of DRMIS in Aceh. In summary, the prototype enabled us to evaluate all DRMIS features and functionalities before real implementation. The data collection and the prototype implementation were facilitated by the DRR-A project (TDMRC, 2010).

\section{RESULTS AND DISCUSSIONS}

\section{Implemented DRMIS}

The complete Internet-based DRMIS has been implemented and is currently accessible via http://tdmrc.unsyiah.ac.id/drmis. The English version of the DRMIS can be accessed through http://tdmrc.unsyiah.ac.id/drmis/index en.html. Figures 6-9 show the graphical user interface of the implemented DRMIS that is discussed in the next sections. Several items and functions from the prototype, as shown in the Figure 5, are adopted in the DRMIS; however, the web layout has been improved to provide a better viewing experience for the users. More thematic layers, such as administrative boundary, infrastructure and geology, are also added to the implemented DRMIS to give better information to users.

As previously discussed, the DRMIS aims to provide disaster related geospatial information which can be publicly accessed without the need of GIS skills and software. Users do not need to arrange the ordering of map layers because the map layers have been carefully arranged so that the selected disaster map is always visible. Users only need to select a disaster type and one aspect of disaster, namely hazards, vulnerability, capacity or risk at a time. This approach is important to ensure one aspect of a disaster layer is displayed without blocking other layers. Only points and lines type layer, such as cities and infrastructure, are placed on top of the disaster layer, whereas other polygon type layers, such as geology and demography, are placed beneath it. Users can adjust the transparency level of a disaster map so that they can examine the disaster layer along with other layers beneath it.

For easy maintenance and security control, the DRMIS has three levels of users' access to the system as follows:

a) System administrator

- $\quad$ Manage users, data and layer hierarchy.

- $\quad$ Manage database and service: insert, delete, update data records and system features. 
b) Authorized user

- $\quad$ Manage attribute data by capturing knowledge of a feature's attributes into a digital format stored on the temporary database or as files.

c) Public user

View maps, query geographic features and print the map.

Although it shares a similar concept as the CEDIM Risk Explorer (Muller et. al., 2006), the DRMIS implementation includes different parameters. As can be seen in Table 3, both systems have different disaster data and components of risk mapping. Besides the three thematic maps as included in the Risk Explorer, we included an additional map (the capacity map) in the DRMIS. We consider that this map is necessary because it is an influencing factor in determining the risk intensity based on Equation (1). Therefore, the risk index adopted in the DRMIS can be uniformly classified for all types of hazards, as mentioned in Table 1 .

In the following subsections, we describe four thematic maps generated by DRMIS. Because of limited space, the description is based on the earthquake and a provincial level map. Please note that other maps for different natural hazards up to the district level are also available in the DRMIS system.

\section{Table 3}

Comparison between CEDIM Risk Explorer (Muller et al., 2006) and the Proposed DRMIS

\begin{tabular}{|c|c|c|}
\hline Parameter & CEDIM Risk Explorer & Proposed DRMIS \\
\hline Disaster data & Historical data of disaster & $\begin{array}{l}\text { Historical data of disaster }+ \text { Primary } \\
\text { (survey) data of risk factors (spatial, } \\
\text { socio-economics, etc.) }\end{array}$ \\
\hline $\begin{array}{l}\text { Components of risk } \\
\text { mapping }\end{array}$ & Unclear & All components listed in Figure 3 \\
\hline $\begin{array}{l}\text { Number of natural } \\
\text { hazards }\end{array}$ & $\begin{array}{l}3 \text { types of hazards in } \\
\text { Germany }\end{array}$ & 10 types of hazards in Aceh \\
\hline Thematic maps & $\begin{array}{l}\text { Hazard, vulnerability and } \\
\text { risk }\end{array}$ & $\begin{array}{l}\text { Hazard, vulnerability, capacity and } \\
\text { disaster risk }\end{array}$ \\
\hline $\begin{array}{l}\text { Architecture of } \\
\text { system }\end{array}$ & Three-tier & Three-tier \\
\hline $\begin{array}{l}\text { Software } \\
\text { configuration }\end{array}$ & ArcIMS server & ArcGIS server \\
\hline Risk index & Unclear & Uniform for all disasters as in Table 1 \\
\hline
\end{tabular}




\section{Hazard Map}

Figure 6 shows the current graphical interface of the DRMIS when a hazard layer is selected. As an example, it shows the earthquake hazard map of Aceh at the provincial level. The earthquake is still one of the most frequent natural hazards in Aceh. The main purpose of the map is to present and visualize the regions that are threatened by the earthquake phenomenon. By knowing the regions that are susceptible to earthquakes, the community is expected to be better prepared to deal with the events and at the same time, anticipate their adverse impact.

For example, any mitigation efforts can be taken to reduce the level of loss or damage. Since the DRMIS is accessible via the Internet, it can be regarded as a tool for disseminating information on hazards to the people at risk and other related parties. Then, by using the hazard map, it is also possible to estimate the potential loss of a region if it is hit by a disaster.

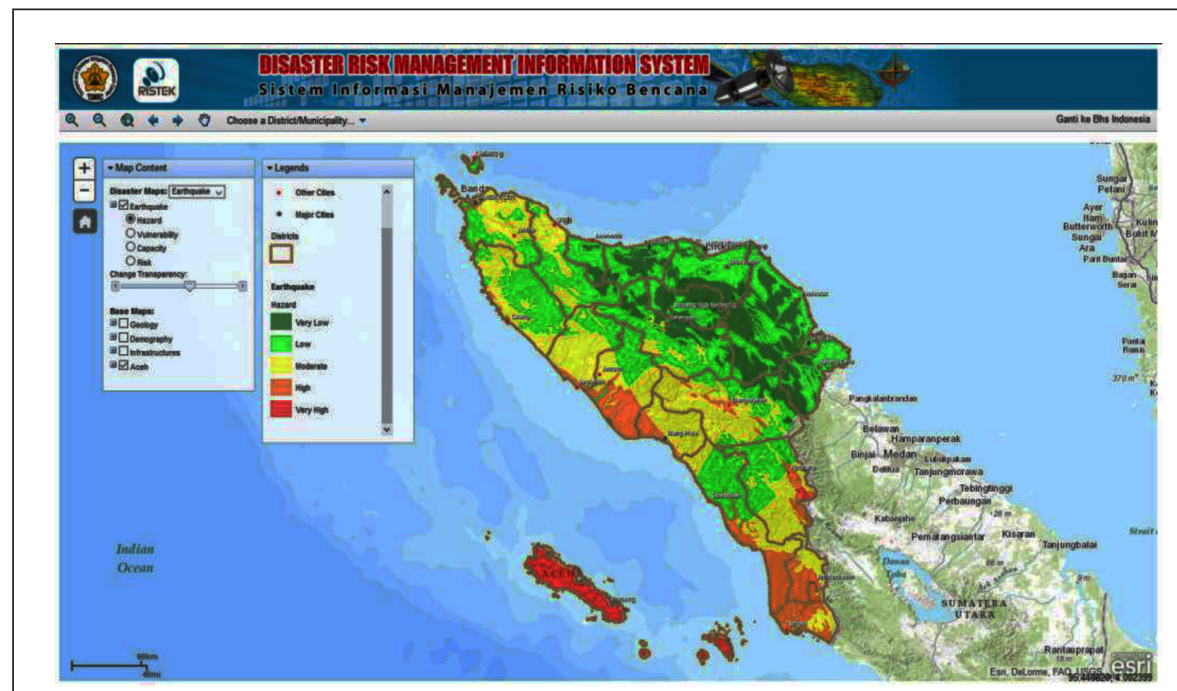

Figure 6. Earthquake hazard map of Aceh.

From the above hazard map, we can see the location and risk level of the earthquake in Aceh province. Five different colors are used to identify intensity levels of hazards (very high, high, moderate, low and very low risk zone). Those levels are represented by red, orange, yellow, green, and dark green colors, respectively, as shown in Figure 6. As can be seen, some parts of Aceh have moderate intensity for earthquakes, indicated by the yellow color, while other parts have low intensity indicated by the green color on the map. 


\section{Vulnerability Map}

A hazard map will not be very useful without vulnerability assessment. Vulnerability is a key issue in risk analysis, which is defined as the degree of loss to one or more given elements resulting from the occurrence of a disaster. The availability of maps and information related to the environment settings is necessary for evaluating the earthquake vulnerability of a region. An example of vulnerability map generated by the DRMIS is shown in Figure 7. As in the hazard map, the level of vulnerability intensities are divided into five levels. From Figure 7, we can see that most parts of Aceh are vulnerable to earthquake at medium level, which is indicated by yellow color on the map. The vulnerability map can be very helpful for the policy-makers as well as the community to come up with evidence-based decisions in reducing their own vulnerabilities. Using this map, the micro-plan for DRR management can be derived, such as the need to secure core assets, like human and infrastructure safety.

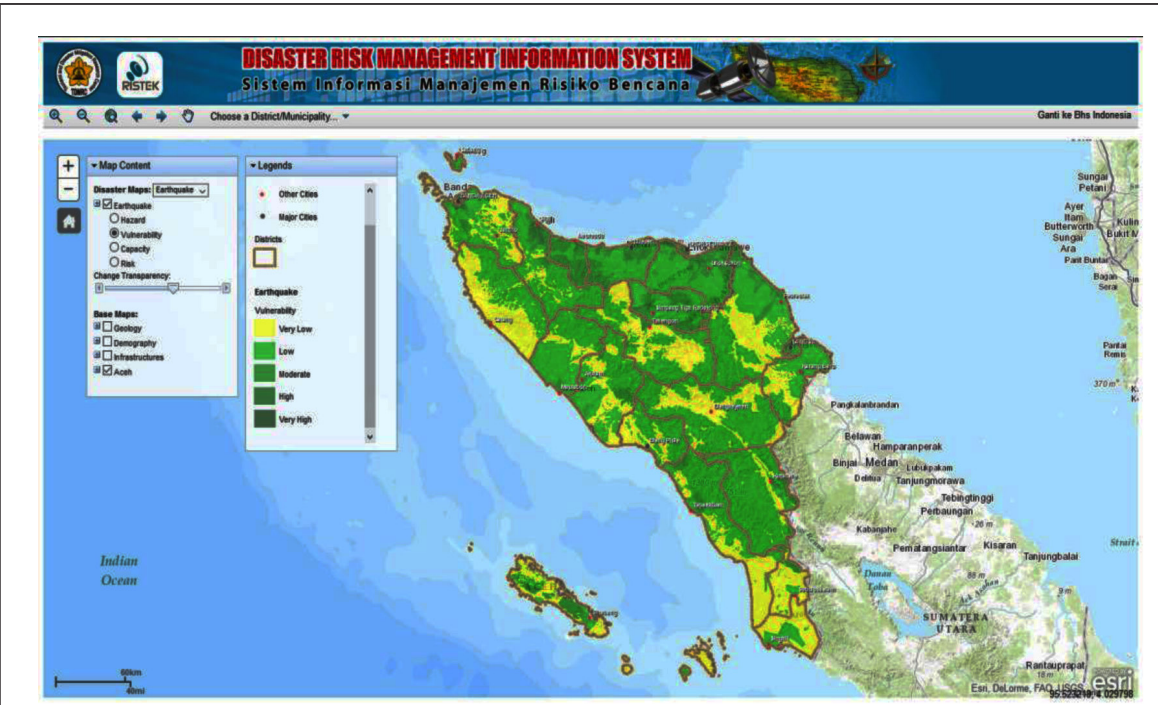

Figure 7. Earthquake vulnerability map of Aceh.

\section{Capacity Map}

Capacity assessment is quite related to the identification of strength or potential resources of a community to anticipate or reduce the impact of disaster. A community whose capacity is high is more prepared to face a disaster. Thus, such a community can recover from a disaster faster than communities with low capacity. Therefore, the level of disaster risk caused by a certain hazard is 
higher for communities whose capacity is low. Capacity level is dynamic, and it depends on social, economic, health and physical preparedness elements. Improving the quality of those elements can increase the capacity level, and in turn, it can decrease the disaster risk level.

Figure 8 shows earthquake capacity map in Aceh generated by DRMIS. Five capacity levels are shown in increasing tones of purple, in which light purple represents very low capacity and dark purple means very high capacity. It can be seen from the map that most areas in Aceh have very low to low capacity level. This map can be used as a basis for targeting areas that need improvement on social, economic and health quality as well as disaster preparedness.

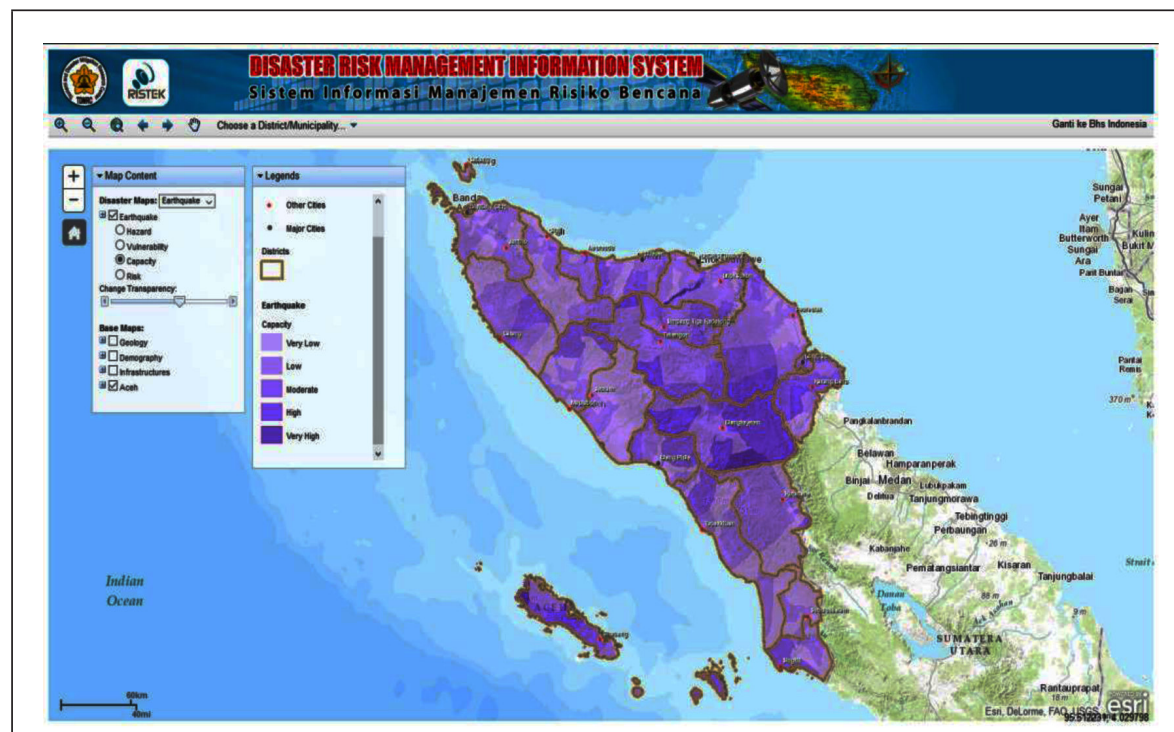

Figure 8. Earthquake capacity map of Aceh.

\section{Risk Map}

Risk is an expected degree of loss caused by a specific disaster that results from the multiplication of the hazard factor and vulnerability. Risk map is definitely required when starting DRR activities. An example of earthquake risk map produced by DRMIS is shown in Figure 9. It is clearly shown that the risk levels of earthquake in Aceh are mostly high and moderate, as marked by orange and yellow colors, respectively. However, several areas have very high earthquake risk, as indicated by red color.

The risk map can increase the people's understanding of the geographical dimension of major disasters. Subsequently, it can help the people to better 
understand the areas that have a high disaster risk. From the government perspective, the risk map plays an important role in the development planning of Aceh towards sustainability. It can also be a valuable tool for communicating risk knowledge to the different community groups. A greater number of people having disaster risk knowledge can certainly enhance the community's resilience. Other disaster risk maps of Aceh can be generated and viewed by choosing the type of disaster under the "map content" menu on the left side of the DRMIS.

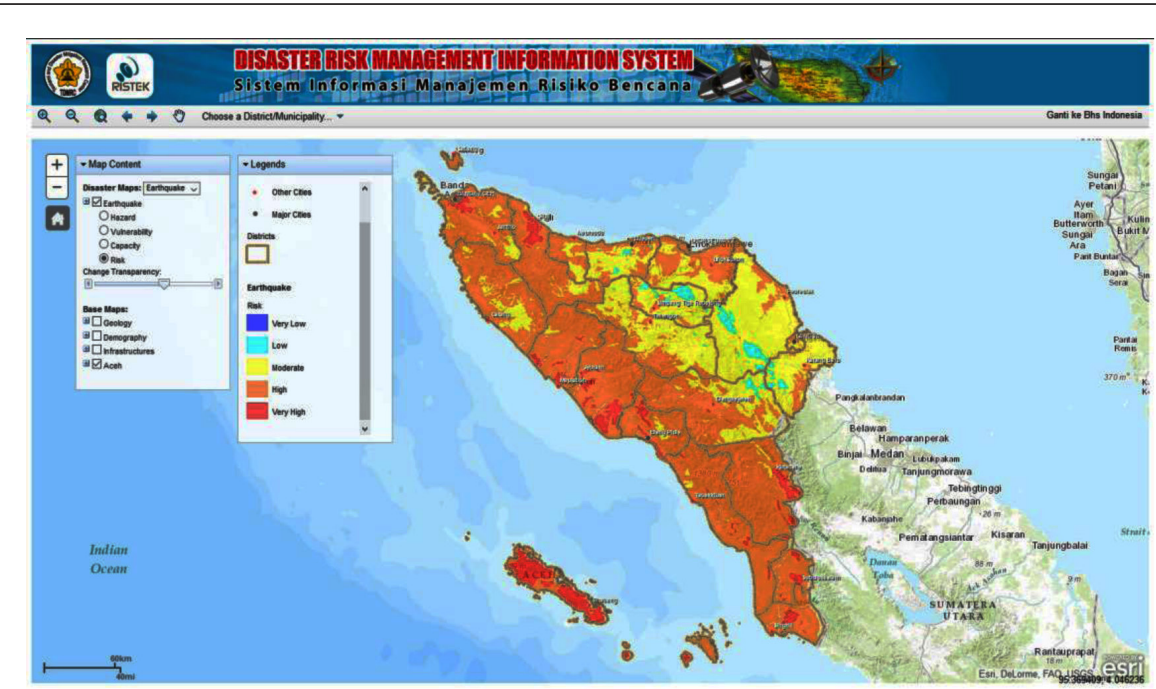

Figure 9. Earthquake risk map of Aceh.

\section{Additional Features}

The DRMIS does not only display hazards, vulnerability, capacity and risks of a disaster, but it also provides additional useful maps, such as infrastructure, demography, geology and administrative maps. These additional maps are not displayed by default, except for the administrative map that shows district and sub-district boundaries as well as a few important cities. Users can view those maps by ticking the checkbox preceding the map title. Each map comprises a few sub-layers, and users can control which layers are to be displayed by checking or unchecking the box preceding the title of each layer.

These maps can give additional information to the disaster-related maps. For example, by displaying the administrative maps on top of a hazard map, users can get ideas about the hazard level of an impending disaster in a district. Another example of the utilization of these additional maps is for the rough 
estimation of damage if a disaster strikes an area. This estimation can be conducted by displaying the infrastructure maps on top of the earthquake hazard map as shown in Figure 10. Based on the maps, a user can calculate how many schools and government facilities are located within the "High" earthquake hazard areas, and the users can use the number to estimate the potential loss in the area if a disaster occurs.

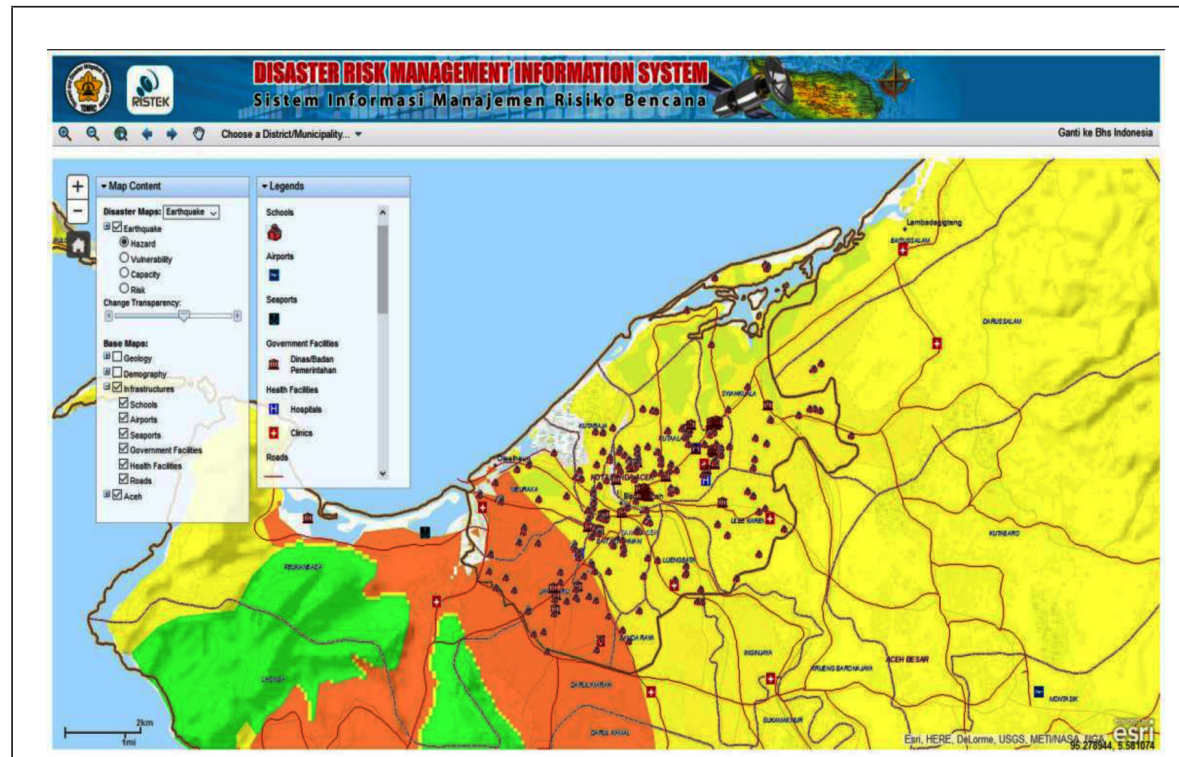

Figure 10. Infrastructure map overlaid on top of earthquake hazard map .

\section{CONCLUSION}

An interactive internet-based Disaster Risk Management Information System, called DRMIS, is proposed. This can be regarded as an effort to strengthen DRR initiaves in the tsunami-hit Aceh province of Indonesia using the Internet and information technology. In addition to geo-database management, the DRMIS is a tool for communicating disaster risk knowledge to the people at risk, government officials and also policy-makers. In this study, we describe the conceptual model, system configuration, network topology, necessary hardware and software, the prototype and the implemented DRMIS. The system was successfully developed and implemented using ArcGIS software packages and related hardware. It can visualize four thematics maps: hazard, vulnerability, capacity and risk maps of the most common disasters in Aceh. The internet-based DRMIS is capable of providing disaster risk information interactively and in an easy-to-understand interface. 


\section{ACKNOWLEDGEMENTS}

The work conducted for this study was supported by Insentif Riset Sistem Inovasi Nasional (Insinas), Ministry of Research and Technology, Republic of Indonesia, in 2013-2014.

\section{REFERENCES}

Abdurrahman, I.R. (2014). GIS as a high performing computing tool for disaster management and control: the Nigerian challenges. In Proceedings of International Conference on Biological, Civil and Environmental Engineering (BCEE-2014), 157-160.

BNPB. (2012). Peraturan Kepala Badan Nasional Penanggulangan Bencana No. 2 tahun 2012 tentang Pedoman Umum Pengkajian Risiko Bencana. BNPB Indonesia.

CENN. (2012). Atlas of natural hazards and risks in Georgia. Retrieved from http://drm.cenn.org

Chang, Y. S., \& Park, H. D. (2004). Development of a web-based geographic information system for the management of borehole and geological data. Journal of Computer \& Geosciences, 30(8), 887-897.

Cheng, Y., Jiancu. L., Wen, J. Z., Xin, Y. Q., \& Xiao L. (2010). Design and development of disaster rapid mapping system in case of earthquake. In proceedings of International Conference on Multimedia Technology (ICMT 2010), 1-4.

Cozannet, G. Le., Bagni, M., Thierry, P., Aragno, C., dan Kouokam, E. (2014). WebGIS as boundary tools between scientific geoinformation and disaster risk reduction action in volcanic areas. Nat. Hazards Earth Syst. Sci., 14, 1591-1598.

Jeberson Ratna Ray, R., \& Sasipraba, T. (2010). Disaster management system based on GIS web services. In proceedings of Recent Advances in Space Technology Services and Climate Change (RSTSCC 2010), 252-261.

KLH. (2007). Laporan Akhir Analisis Potensi Rawan Bencana Alam di Papua dan Maluku (Tanah Longsor - Banjir - Gempa Bumi - Tsunami). Deputi Bidang Pembinaan Sarana Teknis dan Peningkatan Kapasitas, KLH, Jakarta. 
Kohler, P., Muller, M., Sanders, M., \& Watcher, J. (2006). Data management and GIS in the center for disaster management and risk reduction technology (CEDIM): from integrated spatial data to the mapping of risk. Nat. Hazards Earth Syst. Sci., 6, 621-628.

Kraak, M.J. (2004). The Role of the map in a web-GIS environment. Journal of Geographical System, 6(2), 83-93.

Lim, C. C., \& Chang, K. C. (2012). A preliminary study of web-based spatial data analysis feasibility-one of possible solutions for disaster response and management. In Proceedings of International Archives of the Photogrammetry, Remote Sensing and Spatial Information Sciences, 129-134.

Lindell, M., Prater, C., \& Perry, R. (2007). Introduction to Emergency Management (1st ed.). Wiley.

Luiz, A. M., Eliane, H., Janaina, B. S., Eduardo, J. S., Mariana, A. G., Ana, P. C., \& Jose A. Q. (2012). An analysis of geospatial technologies for risk and natural disaster management. Int. Journal of Geo-Inf., 1, 166-185.

Muller, M., Voroghusyn, S., Maier, P., Thieken, A. H., Petrow, T., Kron, A., Buchele, B., \& Watcher, J. (2006). CEDIM Risk Explorer - a map server solution in the project "Risk Map Germany". Nat. Hazards Earth Syst. Sci., 6, 711-720.

Najafabadi, M. O., Hosseini, S. J. F., \& Mirdamadi, S. M. (2009). An ordinal factor analysis of requirements and challenges of information and communication technology system to train private agricultural insurance brokers in Iran. Journal of Information and Communication Technology, 8, 103-114.

Nasaruddin, Munadi, K., Dirhamsyah, M., \& Yuliansyah, D. (2011). A webbased geographic information system for Aceh natural hazards. Journal of Telkomnika, 9(1), 89-98.

Nasaruddin. (2011). Interactive map-based information system for disaster risk reduction in Aceh. In Proceedings of Annual International Workshop and Expo Sumatra Tsunami-Disaster Reduction (AIWEST-DR 2011), 56-61. 
Nasaruddin, Munadi, K., \& Dirhamsyah, M. (2010). Design of disaster risk management information system in Aceh province. In Proceedings of Annual International Workshop and Expo Sumatra Tsunami-Disaster Reduction (AIWEST-DR 2010), 229-234.

Niv, A., Seev, N., \& Moshe, Z. (2002). A system development methodology for ERP systems. Journal of Computer Information System, 42(3), 56-67.

Siekierska, E., \& Williams, P. (2005). Interactive web-based visualization of geo-spatial information for sustainable development decision making. In Proceedings of International Carthographic Conference.

Sutanta, H., Rajabifad, A., \& Ian, D. B. (2010). Integrating spatial planning and disaster risk reduction at the local level in the context of spatially enabled government. In World Conference: Realising Spatially Enabled Societies (GSDI 12), Leuven University Press.

Tahir, M. A. (2007). The needs and geospatial technologies available for disaster management in urban environment. In Proceedings of the

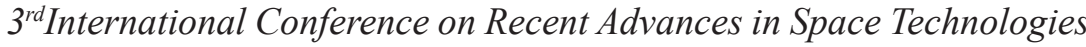
(RAST 2007), 109-114.

TDMRC. (2010). Aceh disaster risk maps (ADRM). Disaster risk reduction for Aceh (DRR-A), UNDP.

UN-APCICT. ICT for disaster risk reduction the India experience. Ministry of Home Affair, India.

Wattegama, C. (2007). ICT for disaster management. Asia-Pacific Development Information Programme.

Yanhua, C., Youpo, S., \& Weiwei, L. (2009). WebGIS resolution for management information system of disaster prevention. In proceedings of IEEE International forum on Information Technology and Applications, 676-679.

Zamli, K. Z., Wan-Hassan, W. A., \& Mohd-Zainuddin, N.M. (2002). Object oriented analysis and the design of large client server applications in a windows environment: an experience. Journal of Information and Communication Technology, 1, 31-50. 
Zemp, H. (2011). ICTs and effective communication strategies: specific needs of information before, during and after disasters. In Proceedings of IEEE International Conference on Innovative Mobile and Internet Services in Ubiquitous Computing, 235-240. 